\title{
Kpamkue сообщенuя
}

удК 579.254

\section{КЛОН $D m \lambda 5$, СОДЕРЖАЩИИ ВСТАВКУ І ТИПА РИБОСОМНЫХ ГЕНОВ Drosophila melanogaster, И ЕГО ХАРАКТЕРИСТИКА}

\section{Р. II. Вашакидзе, Н. 3. Мжавия}

У D. melanogaster более половины всех повторов рибосомных генов содержат вставочные повторяющиеся последовательности в гене $28 \mathrm{~S}$ рРНҚ, среди которых различают два типа, отличающихся по длине и пуклеотидному составу [1]. Вставочные последоватсльности I типа образуют семейство более чем из 100 родственных последоватсльностей ДНК; II типа - локализованы в хромоцентрах $\mathrm{X}$ и $\mathrm{У}$ хромосом и образуют два основных класса размером 1,4 и 3,5 тысяч пар нуклеотидов (т. п. н.). Основной повторяющийся элсмент I типа имеет длину 5 т. л. н., остальныс члены этого семейства-от 0,5 до 1,0 т. п. н. [2]. Вставки I типа, кроме хромоцснтра X-хромосомы, встречаются и в других участках генома [3]. Авторы работы [4] ранее клонировали послсдовательности, соседствующие с внеядрышковыми последовательностями вставок I типа, и показали, что они по крайней мере в некоторых случаях представляют собой мобильные генетические элементы (МГЭ). Для отбора этих последовательностей использовали большой проксимальный фрагмент вставки I типа (рисунок, a, клон DmA2I) [4]. Нами получеи и описан клон $D m A 89$, содержащий фрагмент вставки I типа, который имел внеядрышковую локализацию. Клон содержит последовательность, гомологичную дистальному концу вставки I типа (рисунок, $a$, клоп $B 0,9$ ), и два соседствующих фрагмента, нмеющих в геноме нестабильную локализацию [0]. Клон $D m A 89$ (рисупок, б) содержит пебольшой фрагмент (2,5 т. п. н.) гепомной ДНК $D$. melanogaster и, по-видимому, представляет собой только часть МГЭ.

Целью данной работы являлись клонирование и характеристика фрагмента ДНК L. melanogaster длиной не более 10 т. п. н., содержащего все типы последовательностей ДНК клона DmA89. Методы, использованные в работе, описаны ранее [6-8].

Клонирование последоватсльпости ДНК, содержащсй вставки I типа рибосомных генов и имеоцей внеяцрышковую локализацию, проводили следующим образом.

На первом этапе ${ }^{32} \mathrm{P}$-ДНК клона $B 0,9$ гибридизовали с геномным банком $D$. melanogaster в фате Charon $4 A$ (любезно предоставленным Т. Маниатисом). Средняя длина геномных фрагментов ДНК $D$. melanogaster в библиотеке Charon $4 A$ равна 15 т. I. н. После гибридизации было отобрано около 20 клонов, дающих положительные сигналы. Для отбора клонов, содержащих ДНК с фрагментом вставки I типа $(B 0,9)$, не являющейся частыо рибосомного повтора, проводнлась гибридизация ДНК этих клонов с клонами $D m A 89 A$ и $D m A 89 C$. Таким образом, было отобрано три клона $D m \lambda 1, D m \lambda 3$ и $D m \lambda 5$, ДНК которых гибридизовалась с последовательностью ДНК клонов $D m A 89 A$ и $D m A 89 C$ (не обладающей ядрышковой локализацией) и, следовательно, также не локализовалась в ядрышке [5]. Клон $D m \lambda 5$, содержащий фрагмент ДНК длиной 12,5 т. п. н., был изучен более детально. При обработке ДНК клона $D m \lambda 5$ рестриктазой HindIII образуются четыре фрагмента ДНК вставки. HindIII-фрагменты были субклтонрованы в соответствующий сайт вектора $p B R 322$. Отобранные рекомбинантные клоны обозначены $28, \mu 5, H 17$ (рисунок, в). Рестрикционные карты ДНК клонов стронли, используя рестриктазы HindII, BamHI, EcoRI, EcoRV и нх сочетания. Размеры фрагментов ДНК, образующихся при рестрикции ДНК клопа Din. 5 этими рестриктазами, сопоставляли с размерами фрагментов, образующихся при рестрикции цНК кло- 
нов $M 8$, м5, и H17. Таким образом, оказалось возможным однозначное расположение сайтов рестрикции и построение рестрикционной карты ДНК клона $D m \lambda 5$.

На основании рестрикционной карты была субклоиирована ДНК клонов $⿻ 8$ и $\boldsymbol{M 5}$. Субклон 28.1 получсн рестрикцией ДНК клона $м 8$ рестриктазой ВаmНI и последующим лигировапием. Для получения субклона $M 8.2$ ДНК клона $м 8$ обрабатывали рестриктазами BamHI и EcoRI и лигировали с ДНК $p B R 322$. Для получения субклонов M5.1 и м5.5 ДНК клона 15 обрабатыавали рестриктазами BamHI и EcoRI coответственно и лигировали. Обработкой ДНК субклона м5.5 рестриктазами EcoRV и BamHI и последуюшим лигированием получали субклоны $M 10$ и $м 9$ соответственно.

Для локализации фрагментов, гомологичных $D m A 89 A, D m A 89 C$ и $B 0,9$ последовательностям, ДНК клона Dmג5 расцепляли рестриктазами HindII, BamHI, EcoRI, $E c o R V$ и их комбинациями. Фрагменты ДНК фракционировали в агарозном геле, переносили на нитроцеллюлозный фильтр и гибрндизовали с ${ }^{32} \mathrm{P}$-ДНК $D m A 89 A$, $D m A 89 C$ и $B 0,9$ последовательностей. Для локализации проксимальной гасти вставки I типа рибосомных генов в капестве зонда испотьзовали ДНК клона DMA21.

Қак видно из рисунка, $B$,

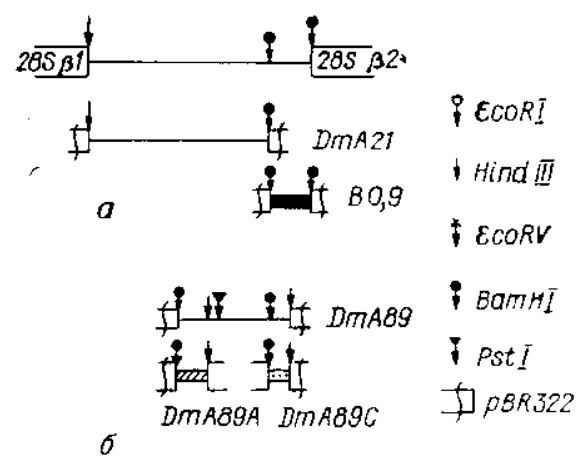

Фрагмент гена 28S p PHK D. melanogaster c длинной вставкой I типа (a) и рестрикционіыс карты ДНК клонов DmA89 (б) и $D m \lambda 5$ (в). Внизу показаны субклонированные фрагменты

Fragment of D. melanogaster 28S rRNA gene with insertion of type I (a) and restriction map of DNA of $D m A 89$ (6) and $D m \lambda 5$ ciones (e). Below are the subcloned fragments

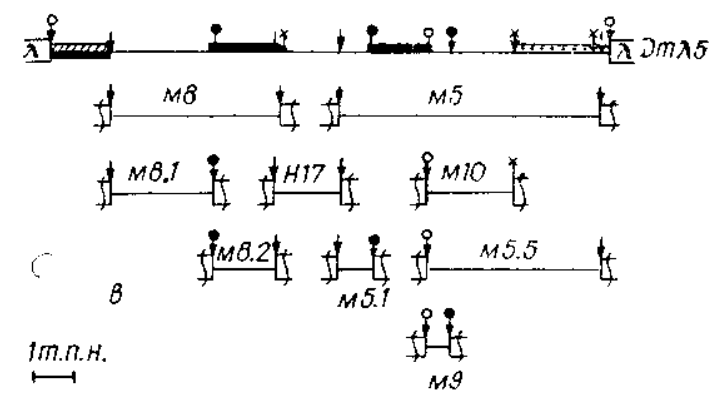

EcoRl-HindII-фрагмегт длиной 1,3 т. п. н. содержит последовательпость, гомологичную Л же в BaflHI-EcoRI- и HindII-BamHI-фрагментах, имеющих плину 1,25 и 1,30 т. п. н. соответвенно. Постецовательность, гомологичная $D m A 89 C$, локализована в $E c o R I$ фрагменте длиной 1,7 т. п. н. Проксимальная часть вставки I типа (клона $D m A 2 l$ ) не входит в состав ДНК киона Dmג5

Для выяснения вопроса, является ли ДНК клона $D m \lambda 5$ целиком повторяющимся элемснтом или ирсдставляет собой скоплсние повторяющихся последовательностей, бына определена повторяемость отдельных участков ДНК клона Dm九5. Для изучения повторяемости фрагмента ДНК использовали метод дот-гибридизацин. Геномную ДНК D. melanogaster (2 мкг) наносили на нитроцеллюлозный фильтр и гибридизовали

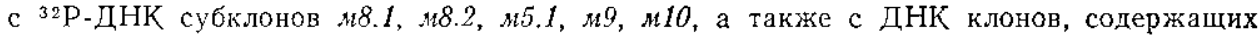
ген актина, ген бслка теплового шока, повторяюшуюся последовательность ДНК гистонов, фрагмент гена $28 \mathrm{~S}$ рРНК и МДГі [6], повторяемость которых точно установлена. Результаты гибридизации показали, что фрагменты ДНҚ, соседствующие с последовательностями, гомологичными $D m A 89 A, D m A 89 C$ и BO,9, уникальны. Повторяемость также оценивали гибридизацией по Саузерну. Геномную ДНК D. melanogaster pacщепляли эндояуклеазой HindIII, фракционировали в $1 \%$-ном агарозном геле, перено-

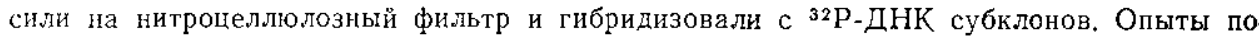
дот-гибридизации и гибридизации по Саузерну дали одинаковые результаты. Повторяемость субклонированных фрагментов $м 8.1, H 17$, м5.1, м9, м10 варьировала от 1 до 5 копий в геноме. ДНК клона м8.2, содержащая последовательность, гомологичную дистальной части вставки I типа рибосомных генов, с обеих сторон фланкирована 
уникальными последовательностями. Это указывает на то, что фрагмент вставки I типа рибосомных генов не входит в состав МГЭ.

Однако в EcoRI-HindII-фрагменте длиной 1,3 т. п. н. (рисунок, в) последовательность, гомологичная дистальной части вставки I типа рибосомных генов, соседствует с генетическим элементом, имеюпим в геноме нестабильную локализацию. Была изучена транскрибируемость ДНК субклонов м8.I и $Н 17$, которая фланкирует ДНК клона м8.2, содержащую фрагмент, гомологичный дистальной части вставки I типа. Суммарную PHK $D$. melanogaster фракционировали в 1,4\%-ном агарозном геле, содержащем $2,2 M$ формальдегид, переносили на нитроцеллюлозный фильтр и гибридизовали с ${ }^{32} \mathrm{P}$-ДНК субклонов м8.1 и H17. О транскрипционной активности судили по интенсивности гибридизации на автораднограммах. В качестве положительного контроля были использованы клоны гистонового и актинового генов, а в качестве отрицательногоклоны, содержащие последовательности сателлитной ДНК и ген теплового шока. Было показано, пто последовательность ДНК субклонов, прилегающая к фрагменту вставки I типа, не транскрибнруется.

Таким образом, фрагменты вставки I типа могут входнть как в состав МГӘ $[4,5]$, так и встречаться в соседстве с уникальными, нетранскрибируемыми последовательностями ДНҚ вне рибосомного повтора.

\section{CLONING AND CHARACTERIZATION OF DM 5 CLONE CONTAINING TYPE I INSERTIONS OF DROSOPHILA MELANOGASTER RIBOSOMAL GENES}

\section{R. P. Vashakidze, N. Z. Mzhavia}

Institute of Molecular Biology and Biological Physics,

Academy of Sciences of the Georgian SSR, Tbilisi

Sum a r y

The $12.5 \mathrm{~kb}$ sequence of DNA containing distal fragment of type I ribosomal repeat insertion and repeating elements of A89 clone from D. melanogaster genomic library has been cloned. It has been shown that fragment of type I insertion in the cloned sequence may be flanked both by the unique nontranscribed sequences and a mobile genetic element.

1. Dawid I. B., Wellaner $P$. K., Long E. O. Ribosomal DNA in D. melanogaster. 1. Isolation and characterization of cloned fragments //J. Mol. Biol.- 1978.-126, N 4.P. $749-768$.

2. Tartof $K$. D., Dawid $I$. B. Similarities and difference in the structure of $\mathrm{X}$ and $\mathrm{Y}$ chromosomal rRNA genes of Drosophila// Nature.- 1976.-263, N 5572.-P. 27-36.

3. Dawid I. B., Botchan P. Sequences homologous to ribosomal insertion occur in the Drosophila genome outside the nucleous organizer//Proc. Nat. Acad. Sci. USA.1977.-74, N 10.--P. 4233-4237.

4. Ribosomal insertion-like elements in D. melanogaster are interspersed with mobile sequences/I. B. Dawid, E. O. Long, P. P. Dinocera, N. L. Pardue//Cell.-1981.-25, N 2.-P. $339-408$.

5. Изучение клона $D m A 89$, представителя нового семейства мобнльных диспергированных генов Drosophila melanogaster / Р. П. Вашакидзе, А. М. Колчинский, Н. А. Тамарина и др. //V Всесоюз. симпоз. «Молекуляр. механизмы генет. процессов»: Тез. докл.-M., 1983.- С. 13.

6. Гены Drosophila melanogaster, кодируюшие богатые полиаденилированные мРНК: клонирование, локализация и экспрессия/А. M. Колчннский, Р. П. Вашакидзе, Е. В. Ананьев и др. // Молекуляр. биология.-1985.-19, № 6.-С. 1569-1577.

7. Uneven distribution of cloned transcribed DME sequences in polytene chromosomes of Drosophila melanogaster /A. M. Kolchinsky, R. P. Vashakidze, E. Yu. Kupert, L. I. Korochkin // Cell Differ-1986-18, N 2.- P. 145-149.

8 Dispersed repeats in Drosophila virilis: elements mobilized by interspecific hybridization /E. S. Zelentsova, R. P. Vashakidze, A. S. Krayev, M. B. Evgenev //Chromosoma.- 1986.-93, N 6.- P. $469-476$

Ин-т молекуляр. биологин и биол. фнзнки АН ГССР, Тбилиси

Получено 12.10 .87 